\title{
Analysis of Scientific Production on Ophthalmia Case Study of Newborn and Its Relationship with the Type of Birth and Preventive Methods: Systematic Review and Meta-Analysis

\begin{abstract}
Danilo Ferreira de Sousa1, Camila Macêdo de Figueirêdo², Cintia de Lima Garcia ${ }^{3}$, Tâmisa Cruz Sampaio de Alencar ${ }^{5}$, Natália Moreira Garcia Feitosa ${ }^{6}$, Francisco Facundo de Matos $\mathrm{Neto}^{6}$, Adalberto Cruz Sampaio ${ }^{2,4}$
\end{abstract}

\section{Abstract}

Objective: To analyze the scientific literature on neonatal ophthalmia and its relation to the type of delivery and prevention methods.

Method: Systematic review and meta-analysis with quantitative and qualitative approach based on the recommendations of the Cochrane Handbook. The databases were searched SciELO, LILACS and MEDLINE/PubMed with use of descriptors in Decs neonatal ophthalmia, conjunctivitis, endophthalmitis and newborns and their descriptors in English present in the MeSH with the inclusion of case reports. Publications were selected between 2004 and 2014 in any language, complete with newborns and individuals diagnosed with neonatal ophthalmia. Studies were excluded if they had no information on the type of delivery and prevention methods.

Results: The relationship between vaginal and cesarean delivery have little statistical significance, while significant, when referring to the presence or absence of ophthalmia with OddsRatio (OR) 1.6, and confidence interval $(\mathrm{Cl}) \mathrm{Cl}(0.168-15.2)$ and its relationship with preventive method (OR) 10.5 with $\mathrm{Cl}(0.668$ to 165.1$)$. The overall result is not statistically significant although it may be considered presenting (OR) of 2.6 with IC (0.753 to 9.278$)$.

Conclusion: There is a significant relationship between mode of delivery, prevention and ophthalmia, the overall outcome of the metaanalysis demonstrated little negativity statistics which should be related to types of studies and quantities available that present enough reduced, highlighting the need for further studies.
1 Discente do Curso de Graduação em Enfermagem da Faculdade de Juazeiro do Norte, FJN.

2 Especialista, Enfermeira, Docente da Faculdade de Juazeiro do Norte, FJN.

3 Mestre, Enfermeira, Docente da Faculdade de Juazeiro do Norte, FJN e da Faculdade de Medicina Estácio, FMJ

4 Especialista, Enfermeiro, Docente da Faculdade Leão Sampaio e Discente do Curso de Medicina da Estácio, FMJ.

5 Especialista, Médica Pediatra, Preceptora da FMUSP.

6 Discente do Curso de Medicina, Estácio. FMJ, Juazeiro do Norte, Ceará.

Contact information:

Adalberto Cruz Sampaio

झ adalberto@leaosampaio.edu.br

Keywords

Ophthamia Neonatorum; Conjunctivitis; Case Reports; Endophthalmitis 


\section{Introducion}

The ophthalmia neonatorum can be understood as an eye infection that commonly occurs in the first month of life. The ophthalmia may have multiple etiologies, but is especially caused by Neisseria gonorrhea and Chlamydia trachomatis [1].

Typically the prevention of infection is made by use of antibacterial agents or silver nitrate. This can sometimes fail in relation to infection caused by Chlamydia. It is widely used for the purpose which it is intended being called Credé method which produces a secondary antibiotic effect [2].

The type of birth is described in some cases as significantly related to the development of the clinical situation. Compared to vaginal birth when there are conditions related to mother like presence of pathogens associated with conditions presented by the child, low immunity, there is great possibility of developing ophthalmia [1]. When it comes to cesarean parturition, other conditions such as rupture of membranes are considered, but not totally excluded. In this sense, one can also consider the use or not of prophylactic methods and the relationship with the development of ophthalmia.

Although not widely in clinical practice frequently many cases this type of infection has been documented. The studies, however, did not clearly emphasize about the possible correlation between the type of birth which the child was submitted and the effectiveness of preventive methods in general in the development of ophthalmia.

The type of birth, the use of preventive methods and positive relation or not the parturition with the development of ophthalmia neonatorum is a subject rarely studied in the scientific community which may suggest that some correlations are not clearly known, for example, the correlation between the three variables mentioned.

Further studies in this direction can provide a better understanding of the factors and conditions associated with the development of the disease. This may enable the development of strategic actions relating to prevention as well as allow greater forecasting newborn's chances to develop ophthalmia.

This study aims to review scientific literature on ophthalmia neonatorum and its relation to the type of birth and prevention methods.

\section{Method}

The aim of the study was designed by systematic review with meta-analysis. It was used as study protocol the Cochrane Handbook's recommendations [3].

This study adopted some criteria for the systematization and assessment of data: selection of guiding questions to be analyzed, establishing the inclusion/exclusion criteria previously listed to select the sample, analysis of texts characteristics and their data from the initial reading titles and abstracts and later by reading the studies in their entirety, interpretation of the results based on their characteristics and criteria for analysis and presentation of the review.

To elaborate the question of the study was used the PICO method on the problem, intervention, comparison, and outcome [4]. It included only case studies, complete, whose participants were neonates diagnosed with ophthalmia neonatorum with any outcome in any language between the years 2004 and 2014. With respect to the exclusion criteria were excluded studies that approached patients in other age not neonatal and those who did not have information on the type of delivery and use of prevention method.

Studies were selected through electronic search in databases Medical Literature Analysis and Retrieval System Online (MEDLINE/PubMed), Literatura Latino-Americana e do Caribe em Ciências da Saúde (LILACS/BIREME) e Scientific Eletronic Library Online (SCIELO).

The descriptors used in the search of the studies were initially present in Decs (Descriptors in Health Sciences). In a first search was used the neonatal ophthalmia and conjunctivitis descriptors where 
Figure 1: PRISMA Flowchart of studies search.

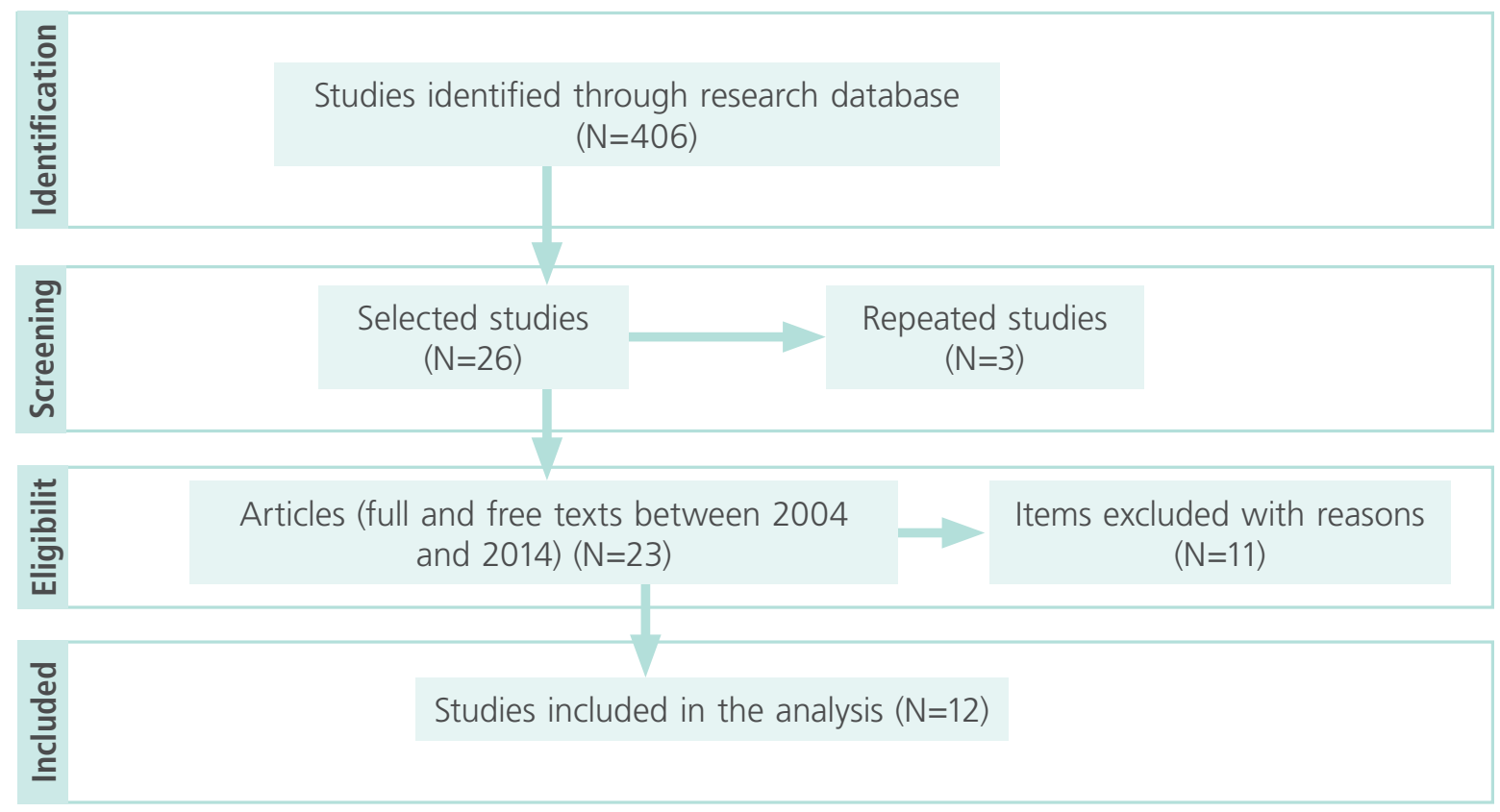

they were found Scielo (2 studies), but none followed the criteria. Also sought with the same descriptors in the Biblioteca Virtual de Saúde (BVS) met 209 and six obeyed criteria.

It was later used the descriptors also Decs endophthalmitis and newborn getting 1 article in SciELO database and 133 in the BVS, where three were LILACS with only 12 met the criteria. For search in PubMed was used the descriptors in MeSH (Medical Subject Headings) ophthalmia neonatorum, conjunctivitis, case reports yielding 61 studies of which seven obeyed criteria.

The Boolean operator of choice was AND in all databases matching the descriptors in pairs in the BVS and SciELO and used the three descriptors in MeSH in PubMed with a single search. 406 references were found by adding up all databases and after applying the inclusion criteria 26 studies remained with the exclusion of 3 repeated and exclusion of studies according to the criteria listed. In all studies that obey the established criteria 12 studies were used, which composes the review.

During the process of selection of studies, two reviewers working independently reviewed the titles and abstracts of studies and the possibility of disa- greement a third reviewer was used for the verdict on the inclusion of the study or not.

In the data extraction process were analyzed some characteristics of the studies as identification (author, year of publication, language), mode of delivery and outcomes. For statistical analysis we used the program BioStat 5.0 and Review Manager 5.3, available from The Cochrane Collaboration. As the characteristic to be analyzed was the type of delivery index and its relationship with the development of ophthalmia was used Odds Ratio (OR) with Confidence Interval $(\mathrm{Cl})$ of $95 \%$ and calculation Mantael-Haenzel heterogeneity.

The risk of bias was assessed according to the Cochrane Collaboration tool. The tool considers six dimensions: allocation sequence generation, allocation concealment, blinding of participants and sta$\mathrm{ff}$, blinding of evaluators, incomplete reporting of outcomes and selective reporting of outcomes.

These characteristics allowed to meet some designs as it has and in what areas and directions of studies are being given to the subject. Figure 1 summarizes the methodological procedures adopted in the research. 


\section{Results and Discussion}

They found 406 references cited in databases and after applying the inclusion/exclusion criteria and other methodological procedures were selected 12 studies that make up this review. Some characteristics of the work are summarized in the following table according to the analysis criteria were established. $\mathrm{N}$ is the number of matching trials for each point analyzed and \% indicates the percentage of related studies. (Table 1)

Despite the growth of the Brazilian scientific production come increasing in recent times, it can be in some cases state that is not ideologically relevant within the global stage, more than $80 \%$ of productions were foreign compared to other parameters. This fact attests to the need to conduct further studies and, in this case related to neonatal ophthalmia. Analyzed the general databases contain relatively few studies on the subject. All bias criteria were reported and appropriate. The following Table 2 contains information on the analyzed studies and on some characteristics later analyzed.

None of the outcomes analyze the relation of the type of delivery specifically between the type of birth with the development of ophthalmia, but comment during the development of their possible relationship in each case and which will be analy-

Table 1. Distribution of studies according to criteria

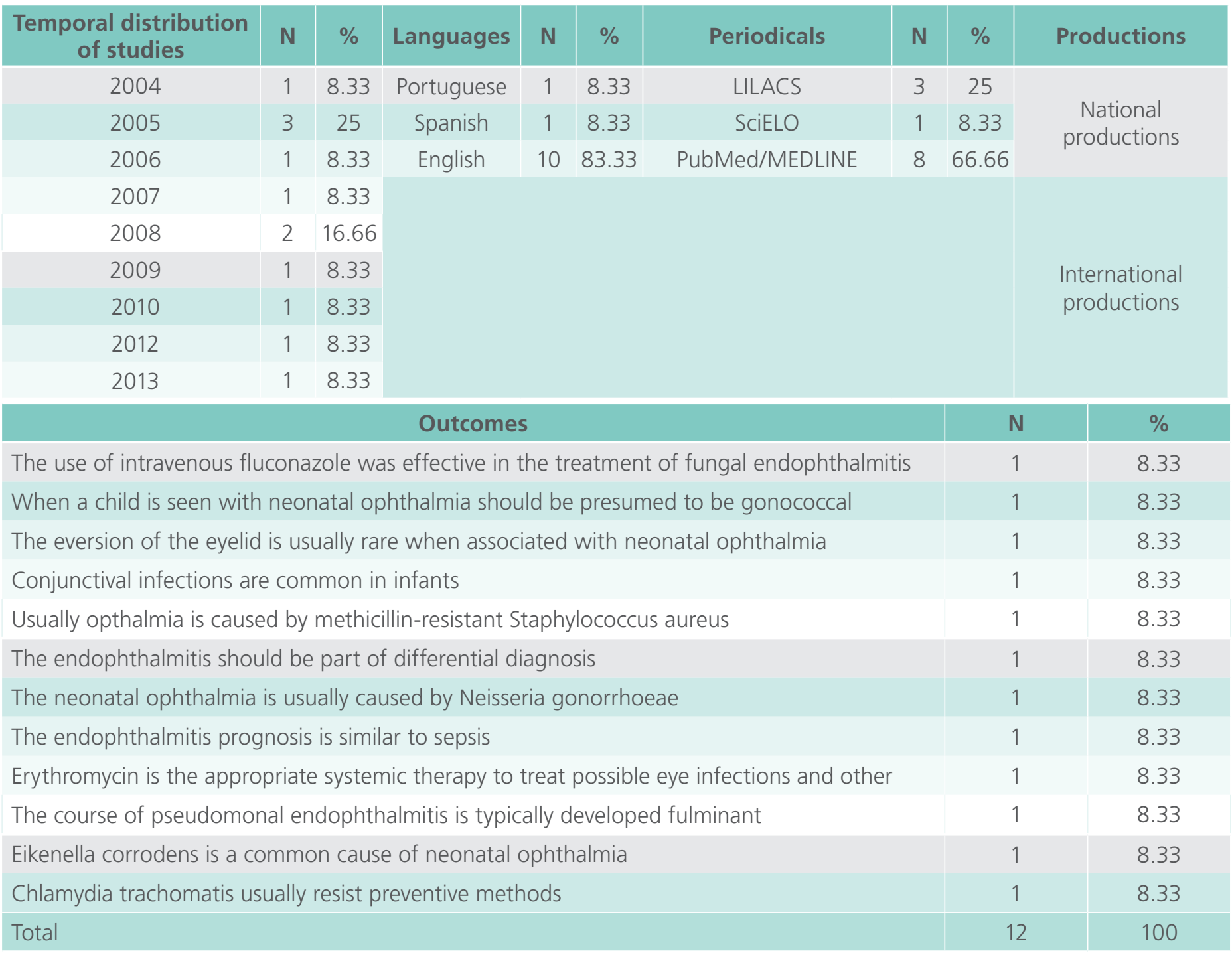


Table 2. Studies analyzed.

\begin{tabular}{|c|c|c|c|c|c|}
\hline Author & Interventions & Outcomes & $\begin{array}{l}\text { Type } \\
\text { of } \\
\text { birth }\end{array}$ & $\begin{array}{l}\text { Preventive } \\
\text { Therapy }\end{array}$ & $\begin{array}{c}\text { Relationship } \\
\text { with } \\
\text { parturition }\end{array}$ \\
\hline Yariv et al., 2004 [1] & Analysis and care inherent in pathology & The neonatal ophthalmia is usually caused by Neisseria gonorrhoeae & Vaginal & Absent & Yes \\
\hline RíO et al., 2008 [2] & Analysis and care inherent in pathology & Conjunctival infections are common in infants & Cesarean & Present & Yes \\
\hline $\begin{array}{l}\text { Dotto et al., } \\
2005[6]\end{array}$ & Analysis and care inherent in pathology & $\begin{array}{l}\text { The use of intravenous fluconazole was effective in the treatment of } \\
\text { fungal endophthalmitis }\end{array}$ & Vaginal & Present & No \\
\hline $\begin{array}{l}\text { Monebenimp } \\
\text { et al., } 2012[8]\end{array}$ & Analysis and care inherent in pathology & $\begin{array}{l}\text { The eversion of the eyelid is usually rare when associated with } \\
\text { neonatal ophthalmia }\end{array}$ & Vaginal & Absent & No \\
\hline Sahu et al., 2006 [9] & Analysis and care inherent in pathology & $\begin{array}{l}\text { Usually opthalmia is caused by methicillin-resistant Staphylococcus } \\
\text { aureus }\end{array}$ & Vaginal & Present & Yes \\
\hline $\begin{array}{l}\text { McCoourt et al., } \\
2010[10]\end{array}$ & Analysis and care inherent in pathology & The endophthalmitis should be part of differential diagnosis & Vaginal & Present & No \\
\hline Basu et al., 2013 [11] & Analysis and care inherent in pathology & The endophthalmitis prognosis is similar to sepsis & Vaginal & $\begin{array}{l}\text { Present (4)/ } \\
\text { Absent (2) }\end{array}$ & $\begin{array}{l}4 \text { Yes/ } \\
2 \text { No }\end{array}$ \\
\hline $\begin{array}{l}\text { Hanh; Giunta, } \\
2007[12]\end{array}$ & Analysis and care inherent in pathology & $\begin{array}{l}\text { Erythromycin is the appropriate systemic therapy to treat possible eye } \\
\text { infections and other }\end{array}$ & Cesarean & Absent & Yes \\
\hline $\begin{array}{l}\text { Figueiredo et al., } \\
2009 \text { [13] }\end{array}$ & Analysis and care inherent in pathology & $\begin{array}{l}\text { The course of pseudomonal endophthalmitis is typically developed } \\
\text { fulminant }\end{array}$ & Cesarean & Present & No \\
\hline $\begin{array}{l}\text { Chhabra et al. } 2008 \\
{[14]}\end{array}$ & Analysis and care inherent in pathology & Eikenella corrodens is a common cause of neonatal ophthalmia & Cesarean & Absent & No \\
\hline Darville, 2005 [15] & Analysis and care inherent in pathology & Chlamydia trachomatis usually resist preventive methods & Vaginal & Present & Yes \\
\hline
\end{tabular}


zed later. In most cases some prophylactic therapy was performed for prevention of ophthalmia which leads some authors relate to the therapeutic effectiveness used. This will be discussed generally, but not specifically for each type of therapy. The metaanalysis results are gathered in Table 3. (Figure 2)

Interpreting a bit of figure each set of studies is represented with a line and a square which represents the effect of the studies and the line confidence interval. The size of the squares represent the weight of each set of studies for the meta-analysis.

Table 3. Correlational meta-analysis according to the purpose of the study.

\begin{tabular}{|c|c|c|c|c|}
\hline $\begin{array}{l}\text { Subgroup } \\
\text { of studies }\end{array}$ & $\begin{array}{l}\text { Positive } \\
\text { events }\end{array}$ & Total & $\begin{array}{l}\text { Odds Ratio } \\
\text { (OR) }\end{array}$ & Ponderosity \\
\hline \multicolumn{5}{|c|}{ Vaginal and Cesarean and relationship with parturition (1) } \\
\hline Vaginal & 8 & 13 & \multirow{2}{*}{$\begin{array}{c}1.6 \\
(0.168-15.2)\end{array}$} & \multirow{2}{*}{0.755} \\
\hline Cesarean & 2 & 4 & & \\
\hline \multicolumn{5}{|c|}{ Vaginal and Cesarean and relationship with prevention (2) } \\
\hline Vaginal & 9 & 13 & \multirow{2}{*}{$\begin{array}{c}2.55 \\
(0.229-22.1)\end{array}$} & \multirow{2}{*}{0.735} \\
\hline Cesarean & 2 & 4 & & \\
\hline \multicolumn{5}{|c|}{$\begin{array}{l}\text { Vaginal with and without prevention and relationship with } \\
\text { parturition (3) }\end{array}$} \\
\hline With & 7 & 9 & \multirow{2}{*}{$\begin{array}{c}10.5 \\
(0.668-165.1)\end{array}$} & \multirow{2}{*}{0.506} \\
\hline Without & 1 & 4 & & \\
\hline \multicolumn{5}{|c|}{$\begin{array}{l}\text { Cesarean with and without prevention and relationship } \\
\text { with parturition (4) }\end{array}$} \\
\hline With & 1 & 2 & \multirow{2}{*}{$\begin{array}{c}10 \\
(0.020-50.4)\end{array}$} & \multirow{2}{*}{0.250} \\
\hline Without & 1 & 2 & & \\
\hline
\end{tabular}

Figure 2: OddsRatio $\mathrm{M}-\mathrm{H}, 95 \% \mathrm{Cl}$.

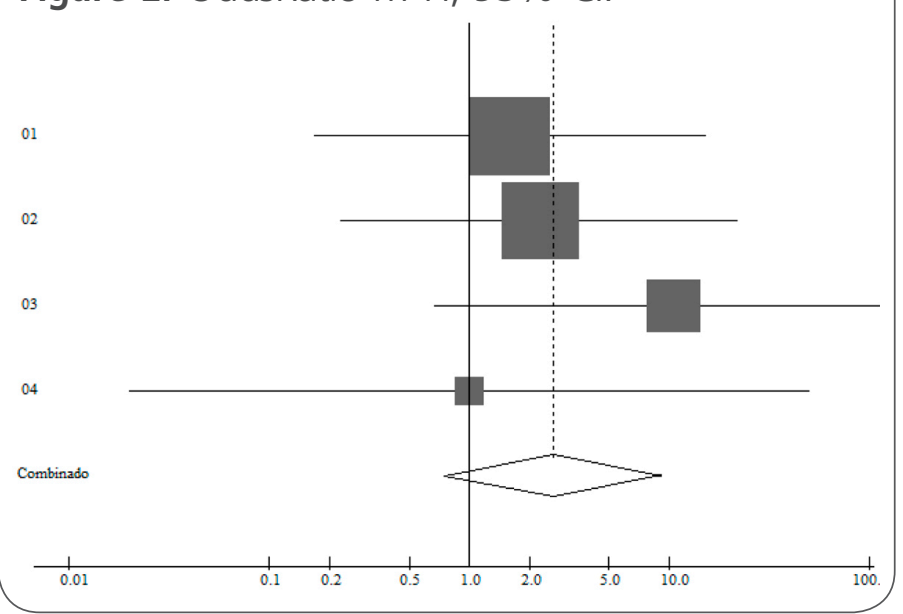

The vertical line represents the lack of effect with diamond symbolizing the end result of the metaanalysis. Most squares are shown on the right side which increases the probability of outcome.

As evidenced by the data shown the relationship between cesarean deliveries and vaginal statistical significance is small, though significant when related to the presence or absence of ophthalmia considering OddsRatio 1.6 and $\mathrm{Cl}$ [0.168-15.2]. With regard to vaginal delivery with a preventive method absence of this relationship is shown having relevant OddsRatio 10.5 and $\mathrm{Cl}$ [0.668-165.1]. Similar event occurs with regard to cesarean deliveries, but these should be given attention since the number of studies displayed and positioning of the authors on the theme.

A small fraction of the final result indicates that it considered the set of analyzed data indicates that the overall result is not statistically significant although it may be considered since the small intersection of diamond and the combined OddsRatio 2.6 with $\mathrm{Cl}$ [0.753 to 9.278]. Although some authors as Dotto et al., 20056, Monebenimp et al., 2012 [8], McCoourt et al., 2010 [10], Basu et al., 2013 [11], Figueiredo et al., 2009 [13], Chhabra et al. 2008 [14] do not mention the possible relationship between mode of delivery and other variables with the development of ophthalmia the relation should be considered.

Considering the ocular complications and even cases of deaths that have evolved to sepsis caused by cases of ophthalmia, the subject should be treated with priority and attention during daily exams which can guide strategic actions both in terms of treatment, as in other care [11]. This may allow a positive greatly optimum outcome.

Although some infections are resistant to most prophylactic methods used in some cases, their use is essential in preventing ophthalmia [9]. This fact is evidenced mainly by the isolated analysis of the use or not preventive methods which have significant relationship in relation to chance of occurrence of the pathology. Here, it is evident once again the im- 
portance of knowledge and use of the same under different circumstances.

\section{Conclusion}

The ophthalmia is characterized by an ocular infection which usually affects infants. It was found that there is a significant relationship between mode of delivery, prevention and ophthalmia, but when analyzing the overall outcome of the meta-analysis show up with little statistical significance.

The use of knowledge of the relationship between mode of delivery and the development of pathology helps in providing care both in prevention and in itself promoting the health of neonates subsidizing better interventions accordingly. Although some authors claim that this relationship is not sufficiently appreciated, the analysis can be seen that the type of delivery should be considered in this context.

Despite the growth of publications on ophthalmia studies and publications also show up scarce mainly concerning national publications. The study and the greatest discoveries about theme is of paramount importance to support strategic actions in various contexts.

It highlights the importance of further development of studies on this issue that can guide strategic actions especially at the primary care level in the prevention or in the identification of ophthalmia. As the clinical condition can lead to various consequences for the newborn special attention to the issue should be given by health professionals.

\section{References}

1. Yariv $\mathrm{F}$ et al. Ophthalmianeonatorum caused by multidrugresistant Neisseria gonorrhoeae. Isr Med Assoc J. 2004 Mar;6(3):180-1

2. Ruiz-Del-Rio, N. et al. Conjuntivitis folicular crónica enel lactante. Arch So cEsp Oftalmol [online]. 2008, vol.83, n.9, pp. 559-561.

3. Higgins JPT, Green S. Cochrane Handbook for Systematic Reviews of Interventions Version 5.1.0. [internet]. The Cochrane Collaboration [2011] [acesso em 19 de maio 2015]. Disponível em: http://www.cochrane-handbook.org
4. Moher, D.; Liberati, A.; Tetzlaff, J.; Altman, D. G. A. Preferred Reporting Items for Systematic Reviews and Meta-Analyses: The PRISMA statement. Annals of Internal Medicine, Philadelphia v. 151, n.4, p. 264-269, jul. 2009. doi: 10.7326/ 0003-4819-151-4200908180-00135. Disponível em: http://rds.epi-ucsf.org/ticr/ syllabus/courses/18/2012/03/29/Lecture/readings/PRISMA\%20 Statement.pdf. Acesso em: 08 jun. 2015.

5. Santos CMC, Pimenta CAM, Nobre MRC. The PICO strategy for the research question construction and evidence search. Rev. Latino-am. Enfermagem. 2007; 15(3):508-11.

6. Jadad AT, Moore RA, Carrol D, Jenkinson C, Reynolds DJ, Gavaghan DJ, et al. Assessing the quality of reports of randomized clinical trials: Is Blinding necessary? Control Clin Trials. 1996: 17:1-12.

7. DOTTO, Patrícia de Freitas et al. Uso do fluconazol endovenoso no tratamento da endoftalmitefúngica endógena: relato de caso. Arq. Bras. Oftalmol. [online]. 2005, vol.68, n.4, pp. 543-546.

8. Walls, Andrew; Wald, Ellen. Neonatal Moraxella osloensis Oftalmia. Emerg Infect Dis. Novembro de 2005; 11 (11): 18031804

9. Monebenimp, Francisca et al. Eversion congénitalebilatérale des paupières: prise en charge d'un casselonl'approcheconservatrice au Centre Hospitalier Universitaire de Yaoundé, Cameroun. Pan Afr Med J. 2012; 11: 34.

10. Sahu, Din et al. Neonatal methicillin resistant Staphylococcus aureus conjunctivitis. Br J Ophthalmol. 2006 Jun; 90(6): 794795

11. McCourt, Eial et al. Isolated group B streptococcal endogenous endophthalmitis simulating retinoblastoma or persistent fetal vasculature in a healthy full-term infant.J AAPOS. 2010 Aug; 14(4):352-5.

12. Basu, Sriparna et al. Neonatal endogenous endophthalmitis: a report of six cases. Pediatrics. 2013 Apr; 131(4)

13. Hanh, Barry; Giunta, Yvonne. Images in Emergency Medicine. June $2007 \mathrm{Vol}$ 49, Issue 6, Pages 823, 831.

14. Figueiredo, Sofia et al. Endogenous endophthalmitis caused by Pseudomonas aeruginosa in a preterm infant: a case report. Cases J. 2009; 2:9304.

15. Chhabra, Manpreet et al. Eikenellacorrodens as a causative agent for neonatal conjunctivitis. J AAPOS. 2008 Oct; 12(5):524-5.

16. Darville, Toni. Chlamydia trachomatis Infectionsin Neonates and Young Children. Semin Pediatr Infect Dis. 2005 Oct; 16(4):23544.

\section{Publish in International Archives of Medicine}

International Archives of Medicine is an open access journal publishing articles encompassing all aspects of medical science and clinical practice. IAM is considered a megajournal with independent sections on all areas of medicine. IAM is a really international journal with authors and board members from all around the world. The journal is widely indexed and classified Q1 in category Medicine. 